\title{
Vozes periféricas, rimas engajadas no Brasil contemporâneo
}

\author{
JOÃO AUGUSTO NEVES*
}

\author{
Resenha de:
}

OLIVEIRA, Roberto Camargos de. Rap e Política: Percepções da vida social brasileira. São Paulo: Boitempo, 2015.

$\mathrm{N}$ o ano de 1992 a comunidade carcerária brasileira ressentia o luto de 111 mortos - em sua maioria homens negros - perpetrados durante o massacre ocorrido na Casa de Detenção de São Paulo, o Carandiru. O maldito episódio promoveu cenas de terror as quais lançaram luzes sobre a situação dos presídios no Brasil, revelando, desse modo, as faces perversas do embuste programado pelo receituário político-econômico adotado nas últimas décadas do século XX no país. A ardilosa mídia corporativa da época, compactuando com os acordos do capital internacional na região latino americana, fez seu trabalho sujo e "jogou para debaixo do tapete" os corpos que revelavam, em alguma medida, as raízes dos problemas sociais brasileiro. Os articuladores dos principais meios de comunicação e seus apoiadores políticos tiveram, no entanto, apesar da tentativa de silenciamento, que ouvir das periferias vozes indignadas, ritmadas por beats e samplers, que denunciavam as tramas do sistema opressor difundido nas bordas da sociedade.

No verão daquele ano quatro jovens negros, oriundos de bairros periféricos da região metropolitana de São Paulo, colocavam nas pistas o seu

\footnotetext{
* João Augusto Neves é Doutorando pela Universidade Estadual de Campinas. Graduado e Mestre em História pela Universidade Federal de Uberlândia, onde também desenvolveu projetos de pesquisa, ensino e extensão ligados às temáticas: Artes, Tecnologias digitais, Educação e Culturas Populares. Atualmente desenvolve pesquisa na área de Sentimentos e subjetividades contemporâneas. Analisa as práticas culturais periféricas e as performances circunscritas ao Funk, ao Rap e ao Punk/Hardcore. E-mail: prof.joaoneves@gmail.com
} 
terceiro álbum. Refiro-me ao disco Raio $\mathrm{X}$ do Brasil, do grupo de rap Racionais MC's, o qual deixava ver em suas composições as angústias dos sujeitos marginalizados que vivenciavam as trágicas consequências das articulações políticas ditadas pela tônica do mercado. Na canção "Fim de semana no parque", por exemplo, após relatar o homicídio de um companheiro, o cantor desabafa:

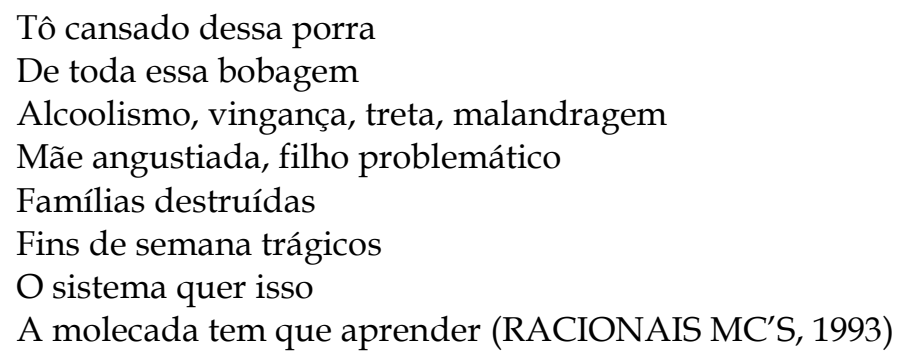

A relação entre o massacre e o "fim de semana no parque", cantada pelos jovens $\mathrm{MC}^{\prime}$ s, não foi entendida na época, pois a interpretação corrente dizia que essas músicas eram "um tipo meio chato" e com batidas que remetiam a "repetições incessantes" (RODRIGUES1 apud OLIVEIRA, 2015, p. 15). Confrontando esses pontos de vistas, e passados cinco anos após o ocorrido na Casa de Detenção, o mesmo grupo de rap lança a emblemática canção “Diário de um Detento" (RACIONAIS MC'S, 1997), composta a partir do relato de um expresidiário do referido cárcere. Registram-se, entre as mixagens sonoras, o cotidiano de um detento e as marcas históricas do massacre ocorrido no Carandiru em outubro de 1992.

Mesmo que as produções dos Racionais MC's combinassem com tantas outras performances de rap e - não podemos nos esquecer - de funk as quais, nas décadas de 1990 e 2000, consolidaram-se como alguns dos principais canais de expressão cultural das periferias brasileiras, os olhares direcionados para estas práticas estavam, e ainda estão de certo modo, preenchidos por estigmas que diminuíam a sua importância social. Nesse sentido, o trabalho de mestrado em História Social de Roberto Camargos de Oliveira, cujo resultado final se beneficiou

${ }^{1}$ RODRIGUES, Apoenan. Rap granha vida nova. Jornal do Brasil, 12 out. 1993. 
com o prêmio "Produção Crítica em Música" concedido pela Funarte em 2013, coloca-se como uma importante obra de produção intelectual engajada capaz de desconstruir preconceitos e dar a devida relevância para o rap nacional enquanto forma estética e política.

Contrariando algumas das leituras que se debruçaram sobre as práticas culturais periféricas, o historiador redimensiona as canções de rap a fim de revelar os aspectos sensíveis, históricos e sociais que as envolvem. Roberto Camargos de Oliveira opta, nesse sentido, por um recorte temporal que satisfaz os anos em que o receituário neoliberal se consolidou no país (1990 - 2000) e que, como demonstra no decorrer do trabalho, fomentou os discursos e posturas críticas dentro do universo do rap. Defende, desse modo, a ideia de que as narrativas criadas pelos rappers, fomentadas pelas trágicas experiências do cotidiano, "elucidam, mesmo que parcialmente, relações de poder estabelecidas, sendo indícios de práticas, ações e valores em negociação e, no limite, em dissonância com a ordem social do capital" (OLIVEIRA, 2015, p. 21).

Partindo dessa premissa, o historiador preocupa-se, nas primeiras páginas do livro, em desmontar a tese, difundida entre os meios de comunicação de massa e reproduzida pelo senso comum, de que o rap conformava um gênero musical sem qualidades estéticas e com pouco significado social. Optando por uma escuta "à contrapelo", o autor desvenda a maneira pela qual essa produção possibilita uma interpretação, dentre outras coisas, dos conflitos sociais no Brasil contemporâneo. Para tanto, o primeiro movimento do livro se propõe a discutir o processo de apropriação feito por jovens brasileiros das práticas circunscritas ao universo da black music, do soul e do hip-hop presentes nos guetos norte-americanos na década de 1970 e disseminados por diferentes canais da indústria cultural em processo de mundialização. Roberto Camargos de Oliveira evidencia usos e bricolagens processados no interior das práticas culturais enraizadas nas periferias do país, as quais tomaram como referência as formas estéticas e os discursos produzidos por sujeitos marginalizados nas grandes cidades estadunidenses. 
Nesse ínterim, as canções formuladas pelos rappers no Brasil passam por uma revisão conceitual, de modo que não mais as percebemos como meras imitações ou fruto de uma transposição sem mediações das formas norte-americanas. Pelo contrário, destaca-se, a cada passo da leitura, como o rap brasileiro ganhou outras tonalidades e se mesclou com experiências das "quebradas" do país.

Interessante notar como o pesquisador não se limita em interpretar o rap apenas no campo da canção. $\mathrm{O}$ autor, subsidiado por uma vasta documentação fonográfica, apresenta o rap enquanto uma prática cultural que se expressa, tanto na forma musical, quanto na postura estética e ética dos sujeitos envolvidos na cena. Percorrendo as páginas do livro aprendemos a ler o objeto em questão como uma manifestação cultural preenchida de sentimentos e significados na qual os agentes protagonistas verbalizam, na canção e nas atitudes assumidas, "as dissonâncias, assinalam a contestação do social no espaço da cidade e alimentam um novo ambiente de reflexão e denúncia" (OLIVEIRA, 2015, p. 51). Desta forma, a pesquisa se delineia a partir do entendimento de que as letras, as mixagens e as performances dos rappers mostram-se como um rico espaço para interpretarmos as complexidades do cotidiano nas periferias das cidades brasileiras. Para isso, o pesquisador se vale de uma vasta documentação que abrange desde discos, cassetes e CD's - gravados de forma artesanal ou profissional -, passando por fontes jornalísticas, audiovisuais, além de uma variada bibliografia que se debruçou sobre o tema.

Seguindo esses vestígios, Roberto Camargos de Oliveira costura os seus argumentos, zelando pelo respeito a trabalhos já realizados sobre o assunto, fazendo indicações e provocando diálogos. Demonstra, com isso, o acúmulo de trabalhos, os quais apresentam diferentes leituras, posturas teóricas e análises interpretativas sobre o rap no Brasil. Em momento algum o autor toma para si a primazia do debate. Suas reflexões são entremeadas por leituras, escutas, debates e discussões com outras vozes, tanto do campo acadêmico quanto de outros espaços que se preocuparam com a temática, seja no próprio universo do rap ou 
em outros meios interessados por essa cultura. Esse exercício narrativo proporciona, além de uma leitura prazerosa, um arsenal de fontes, indicações e referências capaz de munir qualquer interessado em se enveredar pelos labirintos do rap.

A escolha de trabalhar com diferentes tipos de fontes, permitindo que elas the indicassem outros caminhos, levando-o a novos rastros, ampliando, dessa forma, seu corpo documental, contribui para que o historiador demonstre como os sujeitos envolvidos com o rap não estavam alheios às críticas fomentadas pelas mídias hegemônicas, pelos olhares estigmatizantes ou mesmo por tensões provocadas entre seus pares. Na medida em que o rap era escutado, lido e interpretado pela sociedade brasileira, os agentes envolvidos nessa produção procuravam (co)responder as imagens que lhes eram atribuídas. Eles (re)desenhavam as formas impostas e produziam "algo novo no próprio contexto [que viviam] e que diz respeito a uma realidade específica. Sob muitos aspectos, pode-se afirmar que eles (re)inventaram essa cultura musical" (OLIVEIRA, 2015, p. 64).

A partir da escuta atenta e analítica desenvolvida pelo historiador, evidencia-se a construção do "sujeito engajado" nas partituras sonoras do rap. Roberto Camargos de Oliveira apresenta os contornos subjetivos que fazem do "rap compromisso" ${ }^{2}$. Com isso, deparamo-nos com as pulsões que acionaram performances, em diferentes contextos do período analisado, como ferramenta de luta, abrindo brechas a favor de discursos contra hegemônicos. Seguindo nesta trilha, o autor explora como as experiências cotidianas retrabalhadas por essa arte tensionaram as estruturas políticas e iluminaram as contradições do regime neoliberal implantado no país durante as décadas de 1990 e 2000. Impregnados por política e cotidiano, os rappers forjaram um "tribunal da opinião" em que "ao encararem o papel de juízes orientados por uma consciência prática,

\footnotetext{
2 Rap é compromisso. In: SABOTAGEM, 2000, CD. 
comentaram/blasfemaram contra os rumos políticos da sociedade brasileira bem como contra os seus agentes" (OLIVEIRA, 2015, p. 111).

As reflexões discorridas no livro, ao longo dos sete capítulos que compõem a obra, sustentaram-se mediante um denso debate de conceitos caros à historiografia. As análises empreendidas não se esquivaram das implicações teóricas que Roberto Camargos de Oliveira precisou enfrentar ao discutir representação, experiência, cotidiano e política. $\mathrm{O}$ autor traz à sua escrita as referências que lhe serviram de lente para suas análises e, quando necessário, abre parênteses para demonstrar as apropriações conceituais e metodológicas usadas para se pensar tais práticas culturais. Encontramos, vezes ou outra durante a leitura, com nomes consagrados no campo de estudo das culturas populares, sem, no entanto, perder de vista o próprio Camargos e os sujeitos que se engajaram, de alguma maneira, no mundo do rap.

As canções, que ressoam em cada página do livro, diluídas e compostas nas entranhas do capitalismo contemporâneo, filtra experiências e sensibilidades. Desse modo, o uso da noção de "representação" no decorrer do livro alça o rap para outro lugar no social. Essa cultura, no olhar de Roberto Camargos de Oliveira, faz-se por posturas e ações que revelam enfrentamentos com os dispositivos de dominação e com a ordem do discurso. O diálogo com o historiador francês Roger Chartier, nesse sentido, é intenso, haja vista que, como pontua esse estudioso, "esta investigação sobre as representações supõe-nas como estando sempre colocadas num campo de concorrências e de competições cujos desafios se enunciam em termos de poder e de dominação" (CHARTIER, 1988, p. 17).

Essa prerrogativa conceitual, por sua vez, é entrelaçada com a perspectiva da "história vista de baixo", a qual, como Natalie Zemon Davis principal historiadora dessa linha investigativa -, postula uma perspectiva teórica em que as classes populares são assumidas e valorizadas enquanto "atores que, utilizando os recursos físicos, sociais e culturais de que dispunham, agiam no 
sentido de sobreviver, resistir e, as vezes, mudar as coisas" (DAVIS, 1990, p. 9). Desta forma, alimentado por esses campos teóricos, Roberto Camargo sugere que

o rap representa [...] a construção de leituras de mundo ancoradas na ótica de sujeitos que não estavam em ocupações de destaque, não gozavam de prestígio social, nem eram homens ou mulheres conhecidos ou com distinção socioeconômica. Mas eles eram - e são -, entretanto, parte constituinte da sociedade, atuando em diversas esferas como pessoas ativas. (OLIVEIRA, 2015, p. 169)

Destacadas as contribuições no campo historiográfico, vale ressaltar, nos parágrafos conclusivos, a coerência do autor diante da sua pesquisa. As linhas impressas no livro foram forjadas por um trabalho coletivo de longa data, o qual merece ser sublinhado. Roberto Camargos de Oliveira, participa, antes de optar pelo mestrado em História Social, de projetos culturais ligados à cena "underground/independente" na cidade de Uberlândia/MG. Dentre a ações, estão a articulação para a consolidação da CUFA (Central Única das Favelas) importante Organização Não Governamental que fomenta projetos em nível nacional - na região periférica de Uberlândia; participação e promoção de eventos e festivais de bandas Hardcore e Punk na região do triângulo mineiro; produção de vídeos documentários que registram a cena Hip-Hop e outras práticas culturais marginalizadas. E, por fim, compõe, junto com outros coletivos, projetos de extensão ligados a Universidade Federal de Uberlândia.

É clarividente que a articulação do pesquisador, também indicada na introdução do livro, com a cena rap e com outros movimentos sociais em Uberlândia/MG - cidade onde também realizou o mestrado - não se embasou em interesses imediatos para sanar questões da pesquisa. Os sujeitos que fomentavam as práticas circunscritas ao rap na região não ficaram de fora de seu trabalho, sendo-lhes atribuído os devidos créditos no decorrer da obra. Foram, segundo anota Roberto Camargos de Oliveira, conversas informais, convites para shows, organização de encontros e outros eventos ligados ao universo rap que the permitiram, sem perder o senso crítico, compreender os detalhes, os 
silenciamentos, negociações, táticas e estratégias que se misturavam às performances rappers.

Evidencio essa questão pois são poucos os trabalhos acadêmicos que conseguem articular pesquisa, ensino e extensão - conforme reza a função social da Universidade Pública. Assim, da mesma forma que os protagonistas dessa cultura, o historiador também credita à cena um valor particular enquanto trincheira nas "lutas de representações", por isso, engaja-se, enquanto intelectual, na divulgação e aprofundamento de reflexões que já existem no interior desta, e de outras práticas culturais periféricas, e que de alguma maneira circula entre seus protagonistas.

A compreensão sobre engajamento na produção historiográfica, desenvolvida por Hobsbawm, ${ }^{3}$ transparece em cada capítulo do livro e nos trabalhos paralelos desenvolvidos pelo pesquisador. É admirável como Roberto Camargos de Oliveira se arrisca em outras linguagens ou mesmo se envereda para outros campos do saber. Encontramos, caso nos empenhemos em uma rápida pesquisa bibliográfica/biográfica, artigos publicados em revistas de ensino, participação do autor em produção de vídeo documentários, desenvolvimento de oficinas, minicursos e atividades extensionistas, além da organização de encontros e outras ações, todas elas concentradas nas discussões em torno da história, memória, identidade, culturas urbanas e periféricas.

Por essas e outras, a coerência em seu engajamento intelectual, fomentado por um sério e exímio trabalho de pesquisa, faz dessa obra referência obrigatória, como destaca Adalberto Paranhos no prefácio da publicação, para qualquer pesquisa que se aproxime das questões levantas pelo autor.

\footnotetext{
${ }^{3}$ Nas perspectivas desse referenciado historiador, "mecanismos para gerar novas ideias, perguntas e desafios nas ciências a partir de fora são hoje mais indispensáveis que nunca. O engajamento é um mecanismo poderoso desse tipo, talvez no momento o mais poderoso nas ciências humanas. Sem ele, o desenvolvimento dessas ciências estaria em risco". Ver: HOBSBAWM (1998, pp. 138154).
} 


\section{Referências}

CHARTIER, Roger. História Cultural: entre práticas e representações. Lisboa/Rio de Janeiro, Difel/Bertrand Brasil, 1990.

DAVIS, Natalie Zemon. Culturas do povo: sociedade e cultura no início da França moderna. Paz e Terra: Rio de Janeiro: 1990.

HOBSBAWM, Eric. Engajamento. In: HOBSBAWM, Eric. Sobre História. São Paulo, Companhia das Letras, 1998, pp. 138-154.

OLIVEIRA, Roberto Camargos de. Rap e Política: Percepções da vida social brasileira. São Paulo: Boitempo, 2015.

RACIONAIS MC'S. Diário de um detento. Sobrevivendo no inferno, São Paulo: Cosa nostra fonográfica, 1997. CD

Fim de semana no parque. Racionais MC's. Raio X do Brasil. Zimbabwe Records, 1993. LP.

SABOTAGEM. Rap é compromisso. Sabotagem. Rap é compromisso. Cosa nostra fonográfica, 2000. CD. 